\title{
Variación métrica en puntas de proyectil del período Tardío de la Puna de Salta y Jujuy: contribución teórico-metodológica para el estudio de transmisión cultural
}

\section{( María Vardé*}

Fecha de defensa: 15 de Marzo de 2017

Director: Dr. Hernán J. Muscio

Jurados: Dres. Marcelo Cardillo y Norma

Ratto

El objetivo general de esta tesis de licenciatura fue documentar y explicar los patrones morfológicos y de diseño de las puntas de proyectil procedentes de tres sitios del periodo Tardío y Tardío-Inka de la Puna de Salta y Jujuy, abarcando el intervalo temporal comprendido entre $1110 \pm$ 60 y $495 \pm 30$ años radiocarbónicos AP sin calibrar.

El marco explicativo de esta investigación es la teoría de Herencia Dual. Este marco teórico define a la cultura como información socialmente transmitida, que forma parte del fenotipo y que se encuentra bajo la acción de la selección natural y de la toma de decisión, dentro de un proceso de coevolución genética y cultural (Boyd y Richerson, 1985; Durham, 1991). A través del aprendizaje y la toma de decisión, los seres humanos modifican sus fenotipos en respuesta a los ambientes en que se encuentran (Boyd y Richerson, 1985). Los rasgos fenotípicos así adquiridos son transmitidos culturalmente, afectando la adaptación al medio de los individuos. De esta manera, la Transmisión Cultural tiene consecuencias evolutivas a nivel poblacional que están sujetas a la selección natural y otros mecanismos de cambio (Boyd y Richerson, 1985).

El objetivo específico del trabajo fue evaluar el grado de variación métrica y formal de las puntas de proyectil mencionadas, el nivel de covariación de sus variables métricas y el uso de las materias primas, para generar una base empírica que permita discutir la forma en que estos patrones se ajustan a las predicciones de modelos de Transmisión Cultural específicos. De esta manera, se buscó evaluar el modo de transmitir los conocimientos relativos a la fabricación de estas puntas de proyectil, explicar la persistencia y variabilidad de ciertos diseños, y, más generalmente, vincular estas tecnologías con las decisiones que las poblaciones tomaron en lo relativo a sus sistemas de armas y las actividades de caza.

* Instituto de Arqueología, Facultad de Filosofía y Letras, Universidad de Buenos Aires (UBA) - CONICET. 25 de mayo $217,3^{\circ}$ piso (CP C1002ABE), Ciudad Autónoma de Buenos Aires, Argentina. E-mail: mariavardeh@gmail.com
Durante el período Tardío, además de algunas ocupaciones agrícolas en ambientes específicos, los distintos sectores de la Puna estuvieron poblados por sociedades pastoriles que aprovecharon los ambientes locales donde los recursos hídricos y las pasturas permitían el pastoreo de sus rebaños (Albeck, 2007; Olivera y Grant, 2008; Tarragó, 2000). La persistencia de la caza en este contexto fue interpretada como parte integral de una estrategia de diversificación de los recursos y reaseguro frente al riesgo ambiental y de producción (Grant y Escola, 2015; Olivera y Grant, 2008, 2009; Yacobaccio, Madero, Malmierca y Reigadas, 1997/98). En un marco de alta fluctuación temporal de los recursos, la pérdida de presas de alta calidad debe haber sido muy costosa para estas sociedades pastoriles, ya que debió aumentar la presión sobre el consumo de fauna doméstica, cuya disponibilidad también estuvo sujeta a la estocasticidad ambiental (Muscio, 1998-1999; Yacobaccio, et al. 1997-1998). De acuerdo con esto, en esta investigación se propuso el modelo de caza oportunista, según el cual los grupos pastoriles habrían usado el espacio estratégicamente, aprovechando aquellos ambientes que no sólo cumplieron los requerimientos del pastoreo, sino que también proporcionaron oportunidades de encuentro de presas silvestres. Dentro de este modelo, la minimización del riesgo de pérdida de las presas se alcanzaría mediante diseños de armas altamente eficientes. Se espera que, conforme haya aumentado la presión sobre los recursos (tanto naturales como domésticos) debido al crecimiento y/o concentración demográfica, también haya aumentado la fuerza de las estrategias y los mecanismos adversos al riesgo. Por lo tanto, como hipótesis de trabajo, se postuló que los diseños de puntas de proyectil de las armas de arco y flecha del período Tardío de la Puna de Salta y Jujuy estuvieron controlados por la selección cultural, siendo replicados por Transmisión Sesgada, a partir de una Selección Cultural Estabilizadora. Se propuso que este mecanismo actuó sobre diseños de excelente performance en aerodinámica y penetración que minimizaron el riesgo de pérdida de las presas y que para la replicación de estos diseños se seleccionaron materias primas de muy buena calidad. Por la acción de este mecanismo se esperaba hallar patrones de baja variabilidad en los atributos métricos, patrones de covariación fuerte entre pares de variables métricas $y$ altas frecuencias de materias primas de excelente calidad. 
En una primera etapa, en la escala del diseño del artefacto, se efectuó una clasificación paradigmática (sensu Dunnell, 1971) de las puntas de proyectil de la muestra estudiada a partir de rasgos morfológicos y de tamaño. El objetivo con este procedimiento fue evaluar la riqueza de clases del conjunto y su abundancia relativa para obtener información acerca del grado de variabilidad morfológica de la muestra.

En una segunda etapa, en la escala del atributo del artefacto, se efectuó el análisis métrico. Los atributos métricos seleccionados fueron: largo total del limbo, espesor máximo, ancho máximo, ancho medio, ancho de la pieza en la altura de la escotadura, largo de aletas y ancho de cuello de pedúnculo en aquellas piezas pedunculadas. También se incorporó el índice de longitud, con la intención de incluir la dimensión global del diseño (Aschero, 1983) y el área de la sección, cuya fórmula expresa la relación entre las variables intervinientes en la punción del tejido y, por lo tanto, en la capacidad de penetración del artefacto (Hughes, 1998). En relación con las propiedades cinemáticas de los proyectiles, se calculó el nivel de aerodinámica (sensu Ratto, 2003, p. 88). El análisis de estas últimas dos propiedades de los proyectiles permitió evaluar la variabilidad en la performance de los artefactos resultante de la Transmisión Cultural.

Para este análisis, la muestra fue conformada seleccionando los artefactos enteros y aquéllos cuyas fracturas no impidieran la reconstrucción de sus dimensiones totales. Además, se descartaron las piezas que presentaban un grado elevado de reactivación. En total fueron seleccionadas 28 puntas de proyectil provenientes de la excavación de los componentes tardíos de los sitios Cueva Quispe, Cueva Inca Viejo y Cueva Nacimiento I (López, Coloca, Araya, Orsi y Seguí, 2015; Vardé, Seguí y Rucci, 2017; Yacobaccio et al., 2011) (Figura 1).

A partir de la clasificación formal paradigmática, se discriminaron dos morfologías principales en la muestra y los resultados para cada una documentaron patrones diferenciales de variación métrica y covariación de pares de atributos. Una de estas morfologías es la de las puntas triangulares con aletas entrantes y base escotada, la otra es la de puntas triangulares de aletas entrantes y pedúnculo diferenciado.

Ambos subconjuntos presentaron similitudes en términos generales, dado que en promedio el conjunto de puntas de proyectil muestra una baja variación métrica. El análisis de las materias primas del conjunto mostró que todas las rocas que fueron utilizadas para la confección de dichas puntas son de grano fino y excelente calidad para la talla. Además, las rocas no locales se hallan presentes en una elevada frecuencia, especialmente en el subconjunto de puntas apedunculadas. Estas materias primas alóctonas son exclusivamente obsidianas, provenientes de las fuentes de Tocomar, Quirón, Zapaleri, Archibarca y Ona (Figura 1). Teniendo en cuenta todas las puntas de proyectil de las ocupaciones tardías de los sitios analizados (incluyendo aquellas que no fueron seleccionadas para el presente análisis), se evidenció que la alta frecuencia de obsidianas se repetía en cada sitio analizado. En los niveles de ocupación del periodo Tardío de Cueva Quispe, la obsidiana representa el $56,25 \%$ de las materias primas utilizadas para la confección de puntas de proyectil (Yacobaccio et al., 2011); en Cueva Inca Viejo la frecuencia de puntas de obsidiana es del 50\%; finalmente, en Cueva Nacimiento I esta frecuencia asciende al 61,1\% (Vardé et al., 2017). En este trabajo se sugiere que las obsidianas pudieron ser seleccionadas debido a su maleabilidad y calidad para la talla y por la eficacia de sus filos, a pesar de ser una materia prima de menor tenacidad y que requiere el control de ciertas variables para disminuir los riesgos de fractura de los artefactos.

No obstante estas similitudes, se pudo apreciar que las diferencias entre los subconjuntos de puntas pedunculadas y apedunculadas eran significativas. Esto se observó, por ejemplo, en los patrones de correlación, mucho más fuertes y positivos en las puntas apedunculadas. Los diseños de estas morfologías resultaron más estables frente a la variación en el tamaño global de los artefactos, dado que el incremento o la disminución en el valor de una de sus variables se vio acompañado por la misma tendencia en las demás variables de manera significativa. En el subconjunto de puntas pedunculadas se apreció un comportamiento diferente, dado que la relación entre las variables generaba morfologías más alongadas. En relación con la variación métrica, también se observó que los especímenes apedunculados presentaban mayor homogeneidad, especialmente aquellos confeccionados con obsidiana.

Sobre la base de la metodología desarrollada, los datos presentados en esta tesis favorecieron la hipótesis de que la Selección Estabilizadora operó a través de la Transmisión Cultural Sesgada sobre los cabezales líticos de los sistemas de armas del período Tardío, restringiendo la diversidad de diseños. En resumen, se concluyó que la replicación de estos diseños de puntas líticas habría actuado por la transmisión de paquetes de rasgos autocorrelacionados, especialmente en el diseño de puntas triangulares de base cóncava o escotada.

Los patrones resultantes fueron relacionados con el contexto socio-ecológico y se planteó que el contexto selectivo que les dio lugar a través de la Selección Cultural Estabilizadora fue el de una mayor demografía, intensificación de los intercambios interregionales y una marcada intensificación económica. Por otra parte, a partir del buen desempeño de esta tecnología como sistema de 


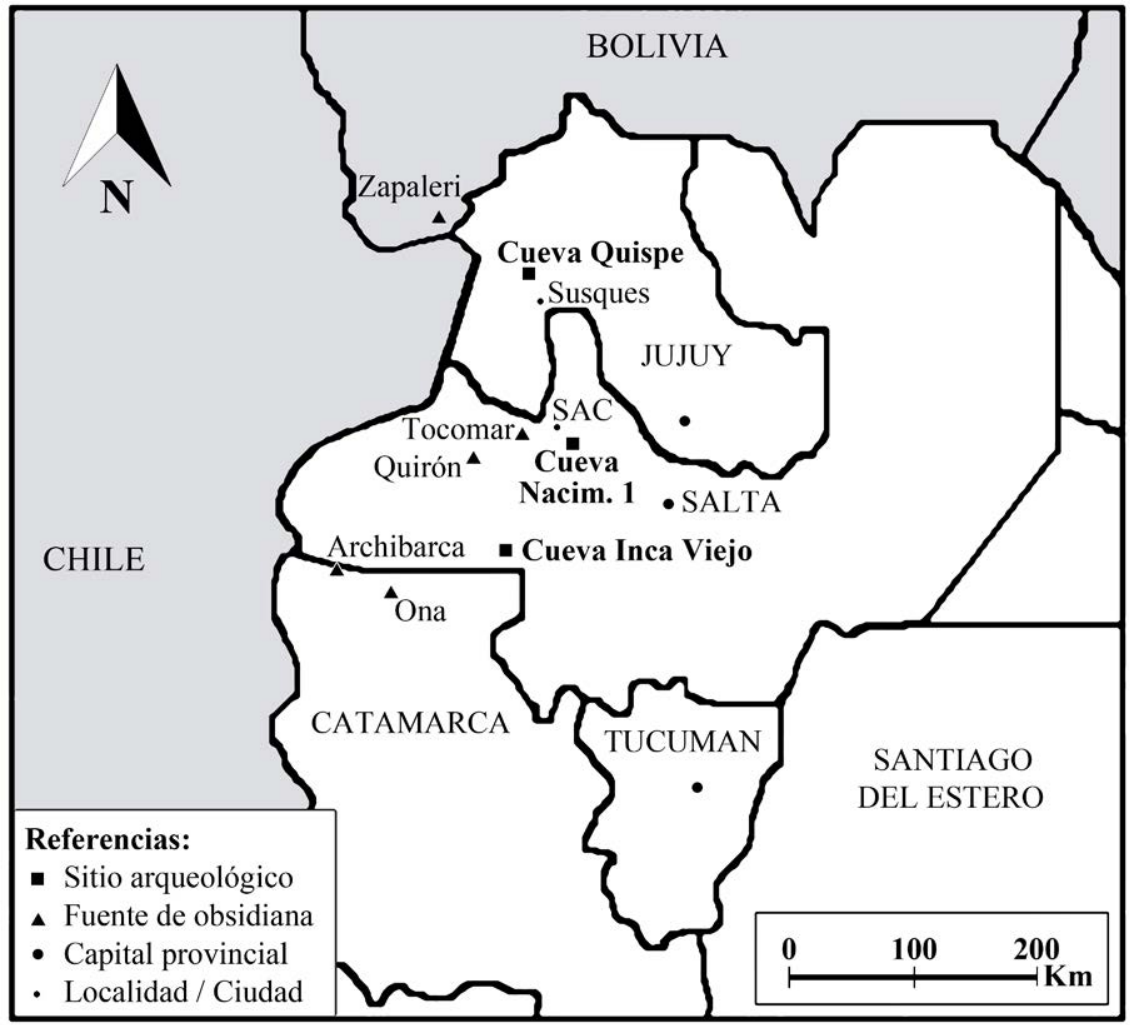

Figura 1. Localización de los sitios arqueológicos y las fuentes de obsidiana.

armas, se planteó la posibilidad de su participación en los enfrentamientos interpersonales, los cuales no pueden ser descartados como contexto de uso del arco y flecha.

De este trabajo se deriva un modelo de clasificación morfológica de rasgos informativos de transmisión que será empleado a futuro como base para análisis de filogenia en muestras más amplias, así como procedimientos adecuados para la contrastación de hipótesis derivadas de la teoría de la Transmisión Cultural en puntas de proyectil en general.

Los resultados obtenidos representan un aporte para la información sobre los sistemas de armas del período Tardío de la Puna de Salta y Jujuy y para la arqueología de los Andes Centro-Sur en general. Por último, se abren nuevas líneas de investigación que serán exploradas en nuevas muestras de contextos ecológicamente diversos de la Puna y para períodos de tiempo más amplios.

\section{Referencias citadas}

» Albeck, M. E. (2007). El Intermedio Tardío: Interacciones económicas y políticas en la Puna de Jujuy. En V. Williams, B. Ventura, A. Callegari y H. Yacobaccio (Eds.), Sociedades Precolombinas Surandinas. Temporalidad, Interacción y Dinámica cultural del NOA en el ámbito de los Andes Centro-Sur (pp. 125-145). Buenos Aires: TANOA.
» Aschero, C. A. (1983). Ensayo para una clasificación morfológica de artefactos líticos aplicada a estudios tipológicos comparativos. Informe al CONICET. Manuscrito inédito.

» Boyd, R. y Richerson, P. J. (1985). Culture and the Evolutionary Process. Chicago: University of Chicago Press.

» Dunnell, R.C. (1971). Systematics in Archaeology. Nueva York: Free Press.

»Durham, W. H. (1991). Coevolution: Genes, Culture and Human Diversity. Palo Alto: Standford University Press.

» Grant, J. y Escola, P. (2015). La persistencia de un modo de producción doméstico durante el Período Tardío: el caso de Corral Alto (Antofagasta de la Sierra, Argentina). Estudios Atacameños, 51, 99-121.

» Hughes, S. (1998). Getting to the point: evolutionary change in prehistoric weaponry. Journal of Archaeological Method and Theory, 5(4), 345-408.

» López, G., Coloca, F. I., Araya, S., Orsi, J. P. y Seguí, S. (2015). El sitio Cueva Inca Viejo, Salar de Ratones, Puna de Salta: evidencia arqueológica y procesos de interacción macrorregional. Relaciones de la Sociedad Argentina de Arqueología, XL, 45-71.

» Muscio, H. J. (1998-1999). Tendencias en la variabilidad ambiental de la Puna Argentina: Implicancias para 
la ecología humana prehistórica y para los paisajes arqueológicos. Cuadernos del Instituto Nacional de Antropología y Pensamiento Latinoamericano, 18, 271296.

"Olivera, D. y Grant, J. (2008). Economía y ambiente durante el Holoceno tardío (CA. 4500-400) de Antofagasta de la Sierra (Puna Meridional argentina). En A. Acosta, D. Loponte y L. Mucciollo (Eds.), Temas de Arqueología: Estudios Tafonómicos y Zooarqueológicos (I) (pp. 99-131). Buenos Aires: Fundación Amigos del Instituto Nacional de Antropología y Pensamiento Latinoamericano.

》 Olivera, D. y Grant, J. (2009). Puestos de altura de la Puna argentina: zooarqueología de Real Grande 1 y 6 y Alero Tomayoc. Revista del Museo de Antropología, 2, 151-168.

» Ratto, N. (2003). Estrategias de caza y propiedades del registro arqueológico en la Puna de Chaschuil (Departamento Tinogasta, Catamarca, Argentina). (Tesis Doctoral inédita), Universidad de Buenos Aires, Argentina.
" Tarragó, M. (2000). Chacras y pukara. Desarrollos sociales tardíos. En M. Tarragó (Ed.), Nueva Historia Argentina. Los Pueblos Originarios y la Conquista (pp. 257300). Barcelona: Sudamericana.

» Vardé, M., Seguí, S. y Rucci, L. (2017). Análisis del material arqueológico de la Cueva Nacimiento 1, Puna de Salta (Argentina), Período Tardío. Cuadernos del Instituto Nacional de Antropología y Pensamiento Latinoamericano (Series Especiales), 4(3), 31-41.

" Yacobaccio, H. D., Catá, M. P., Morales, M. R., Solá, P., Alonso, M. S., Rosenbusch, M., Vázquez, C., Samec, C., Oxman, B. y Cáceres, M. (2011). El uso de cuevas por pastores andinos: El caso de Cueva Quispe (Susques, Puna de Jujuy). En H. Muscio y G. López (Eds.) Arqueología de la Puna argentina: Perspectivas Actuales en el Estudio de la Diversidad y el Cambio Cultural (pp. 33-48). Oxford: Archaeopress.

"Yacobaccio, H. D., Madero, C., Malmierca, M. y Reigadas, M. C. (1997-1998). Caza, domesticación y pastoreo de camélidos en la puna argentina. Relaciones de la Sociedad Argentina de Antropología, XXII-XXIII, 389-428. 